\title{
EFEITOS DO ATRASO NA COLHEITA E DO PERÍODO DE ARMAZENAMENTO SOBRE O RENDIMENTO DE GRÃOS INTEIROS DE ARROZ DE TERRAS ALTAS
}

\author{
Effect of harvest moisture and storage period \\ upon the yield of whole grains in the upland rice processing \\ Gilson José Teixeira Ribeiro ${ }^{1}$, Antônio Alves Soares ${ }^{2}$, \\ Moisés de Souza Reis ${ }^{3}$, Vanda Maria de Oliveira Cornélio ${ }^{3}$
}

\begin{abstract}
RESUMO
O presente trabalho foi desenvolvido com o objetivo de avaliar os efeitos do atraso da colheita sobre o rendimento de grãos inteiros no beneficiamento de 12 cultivares e linhagens de arroz, bem como diferentes períodos de armazenamento sobre a recuperação da porcentagem de grãos inteiros. Para tanto, procedeu-se à avaliação da umidade dos grãos e ao rendimento de grãos inteiros de amostras de arroz colhidas aos 0, 7, 14, 21 e 28 dias após a maturação. Foram armazenadas também amostras de grãos para determinação do rendimento de grãos inteiros aos 30, 60, 90, 120 e 150 dias após a colheita de cada cultivar e linhagem. Os maiores rendimentos de grãos inteiros são obtidos quando a colheita é realizada com umidade em torno de 20\%; a cultivares Caiapó e a linhagem CNAs 8983 toleram atraso na colheita sem maiores prejuízos ao rendimento de grãos inteiros. O armazenamento dos grãos por mais de 90 dias mantém ou favorece o rendimento de grãos inteiros no beneficiamento.
\end{abstract}

Termos para indexação: Oryza sativa, rendimento industrial de grãos.

\section{ABSTRACT}

The present work was develop with a view to evaluating the effect of the delay of harvest on grain moisture and whole grain yield in the processing of 12 rice cultivars as well as the different storage periods upon the recovery of the percentage of whole grains of samples of rice (Oryza sativa L.) harvested at 0, 7, 14, 21 and 28 days after maturation, respectively. Grain samples were also stored determination of the yield of whole grains at 30, 60, 90, 120 and 150 days after harvest of each cultivar. The results showed that the highest yield of whole grains and obtained when harvest is performed with moisture around $20 \%$, the cultivars Caiapó and CNAs 8983 tolerate delay in harvest without further damages to grain yield and the grains for over 90 days maintains of favors the yield of whole grains in processing.

INDEX TERMS: Oryza sativa, milling yield.

(Recebido para publicação em 17 de dezembro de 2003 e aprovado em 26 de agosto de 2004)

\section{INTRODUÇÃO}

O arroz (Oryza sativa L.), após atingir a maturidade fisiológica, que ocorre em torno de 28 a $30 \%$ de umidade, permanece no campo aguardando a redução de umidade para ser colhido (SOARES, 2001). Para a maioria das cultivares, há um consenso de que a colheita deva ser realizada quando os grãos apresentarem umidade de 20 a 22\% (EPAMIG, 1983; HESSE, 1983; FERNANDES e AMORIM NETO, 1987; CASTRO et al., 1999).

A colheita antecipada ou tardia afeta a produção de grãos e a qualidade do produto. Os prejuízos da colheita muito cedo são: elevada ocorrência de grãos verdes, gessados e mal formados, que não completaram o seu desenvolvimento. Por outro lado, se a colheita for feita tardiamente, com os grãos apresentando umidade muito baixa, ocorrem perdas por degrana natural, por acamamento, ataque de insetos, pássaros e roedores (EMBRAPA, 1999; SOARES, 2001). Entretanto, o maior prejuízo produzido pela colheita tardia (umidade abaixo de $18 \%$ ) é a redução no rendimento de grãos inteiros no beneficiamento, reduzindo drasticamente o valor comercial do produto (EPAMIG, 1983; HESSE, 1983; BRESEGHELLO e STONE, 1998; EMBRAPA, 1999). Tem-se observado também uma resposta diferenciada das cultivares de arroz com relação à quebra de grãos durante o beneficiamento, com o atraso da colheita, ou seja, algumas cultivares são mais tolerantes à colheita tardia do que outras.

1. Estudante de graduação, curso de agronomia da Universidade Federal de Lavras/UFLA - Caixa Postal 3037 - $37200-000$ - Lavras, MG.

2. Professor do Departamento de Agricultura da UFLA. aasoares@ufla.br

3. Epamig - Centro Tecnológico do Sul de Minas. Caixa Postal 176 -37200-000 - Lavras, MG. moireis@hotmail.com, vanda.cor@bol.com.br 
RIBEIRO, G. J. T. et al.

Castro et al. (1999) mencionaram uma variação de 49 a 61,8\% de grãos inteiros para 11 cultivares de arroz de sequeiro, considerando a umidade adequada de colheita.

Avaliando sete épocas de colheita: 30, 35, 40, 45, 50, 55 e 60 dias após floração sobre a qualidade de grãos e seis cultivares de arroz de várzea no Estado do Rio de Janeiro, Fernandes e Amorim Neto (1987) verificaram que os mais elevados percentuais de grãos inteiros foram obtidos com colheitas feitas em torno de 40 dias após a floração.

Em trabalho realizado pela Epamig (1983) utilizando quatro cultivares de arroz irrigado e oito épocas de colheita (30, 35, 40, 45, 50, 55, 60 e 65 dias após floração), foi constatado que para todas as cultivares o maior percentual de grãos inteiros foi obtido com a colheita aos 30 dias após a floração.

Variações no rendimento de grãos inteiros no beneficiamento são mais freqüentes no arroz de terras altas do que no arroz de várzea, uma vez que está mais sujeito aos efeitos das alterações climáticas, sobretudo, estresse hídrico. O grão de arroz se quebra no beneficiamento em razão de várias causas e a principal delas deve-se ao fato de os grãos já saírem do campo com rachaduras, ocasionadas por reidratação devido à chuva, orvalho ou umidade relativa do ar muito elevada, e por contração, devido à desidratação nas horas mais quentes do dia. (CASTRO et al., 1999; SOARES, 2001).

Há evidências também de que o tempo de armazenamento contribui para aumentar a porcentagem de grãos inteiros no beneficiamento (CASTRO et al., 1999). Uma das prováveis causas é a menor aderência da casca ao endosperma, à medida que aumenta o tempo de armazenamento, facilitando sua remoção durante o descascamento, contribuindo, assim, para diminuir o índice de quebra.

Diversas cultivares melhoradas de arroz de terras altas foram lançadas recentemente para o plantio em Minas Gerais, e pouco se sabe sobre o comportamento delas quanto à tolerância ao atraso da colheita no que diz respeito ao rendimento de grãos inteiros no beneficiamento, sobretudo das cultivares de grãos agulhinha, como a Confiança, Canastra, Primavera e Carisma.

Assim, com o presente trabalho teve-se por objetivo determinar as variações de umidade de grãos em função do atraso na colheita; avaliar o efeito do atraso na colheita no rendimento de grãos inteiros no beneficiamento de diferentes cultivares e linhagens de arroz de terras altas, e quantificar o aumento ou a recuperação da porcentagem de grãos inteiros no beneficiamento mediante diferentes períodos de armazenamento de grãos.

\section{MATERIAL E MÉTODOS}

Este trabalho foi realizado em Lavras - MG, utilizando grãos oriundos de parcelas do ensaio comparativo avançado de arroz de terras altas do programa de melhoramento de arroz da UFLA/Epamig/Embrapa Arroz e Feijão, conduzido na Fazenda Experimental da Epamig, no período de novembro de 2000 a abril de 2001. O referido experimento, que é constituído de 20 tratamentos (cultivares e linhagens), foi instalado em delineamento de blocos ao acaso com três repetições. As parcelas foram constituídas de cinco linhas de $5 \mathrm{~m}$ de comprimento, espaçadas de $0,4 \mathrm{~m}$ entre si. A densidade de semeadura foi de 60 a 70 sementes. A adubação e os tratos culturais foram realizados de acordo com Soares (2001).

Dos 20 materiais testados no ensaio comparativo avançado, foram selecionados sete cultivares e cinco linhagens para realizar o presente trabalho, ou seja, as cultivares Guarani, IAC 202, Caiapó, Confiança, Canastra, Primavera e Carisma e as linhagens CRO 97505, CNAs 8957, CNAs 8983, MG 1043 e CNAs 8824.

Foram colhidos 250 g de grãos, na maturação, ou seja, época adequada de colheita, e aos 7, 14, 21 e 28 dias após essa época. Em seguida, foram determinadas a umidade e a subseqüente secagem ao sol até $13 \%$ de umidade, quando, então, processaram-se a determinação da renda de beneficio e o rendimento de grãos inteiros no beneficiamento, utilizando o testador de arroz Suzuki.

Após a colheita, secagem e pesagem dos grãos da área útil das parcelas, foi tomada uma amostra de 1,5 kg de cada cultivar e linhagem para armazenamento e posteriores avaliações. Os testes de rendimento industrial e de rendimento de grãos inteiros foram realizados aos 30, 60, 90, 120 e 150 dias após a colheita de cada cultivar e linhagem.

\section{RESULTADOS E DISCUSSÃO}

Embora a colheita do arroz deva ser realizada quando os grãos atingirem a umidade de $20 \%$ a $22 \%$, isso nem sempre é possível na prática, pois depende das condições climáticas, uniformidade de maturação da cultivar, disponibilidade de máquinas, transporte, secador, etc. Mesmo em experimenos, a colheita também nem sempre é feita no momento mais adequado, uma vez que as cultivares e linhagens têm ciclos diferentes e são, portanto, colhidas em dias diferentes, em que a umidade do ar e do solo e a temperatura influem na umidade dos grãos. Por isso, determinou-se, na colheita, a umidade dos grãos de todos os materiais testados, bem como a perda de umidade com o atraso planejado da colheita.

Ciênc. agrotec., Lavras, v. 28, n. 5, p. 1021-1030, set.out., 2004 
Efeitos do atraso e do período de armazenamento sobre o...

Os resultados de média de umidade de cada material na colheita aos 7, 14, 21 e 28 dias após são mostrados na Tabela 1. Considerando todas as cultivares e linhagens, a colheita foi realizada com uma umidade média de $19,6 \%$, com variação de 15 a 23\%. Portanto, a maioria delas foi colhida com a umidade próxima da adequada. $\mathrm{O}$ atraso maior na colheita ocorreu com as cultivares Confiança (15\% de umidade) e Canastra ( $16 \%$ de umidade). Por serem materiais de ciclo mais longo, a colheita foi realizada num período mais seco, já no final do período das chuvas.

A maior redução de umidade dos grãos no campo ocorreu no período compreendido entre a umidade adequada de colheita até aos 7 dias após, ou seja, 3\%, seguida do período de 7 a 14 dias, quando a redução média foi de 1,1\%. A partir dos 14 dias, a redução de umidade foi menor (Tabela 1), sendo o resultado dos grãos da cultivar Confiança prejudicado, pois de 14 para 21 dias, aumentou a umidade em $2 \%$, ocasionado por uma chuva antes da colheita, afetando, assim, a média dos demais materiais. A redução mais intensa da umidade dos grãos, na média das cultivares e linhagens, aos 7 dias e 14 dias após a colheita, é mais bem visualizada na Figura 1.

As avaliações da umidade de grãos na colheita e aos 7, 14, 21 e 28 dias após, para cada cultivar e linhagem, são também mostradas na Figura 2 e Figura 3. Em ambas as figuras infere-se claramente que, embora na colheita as umidades sejam bastante divergentes, à medida que as cultivares e linhagens permanecem no campo, há uma convergência de umidade, tendendo para $14 \%$, quando, então, entram em equilíbrio com a umidade do ar. Pode-se observar também que, de modo geral, os materiais testados tiveram uma tendência muito semelhante no tocante à redução de umidade, quando se atrasou a colheita no campo.

TABELA 1 - Umidade dos grãos (\%) de 12 cultivares e linhagens de arroz de terras altas em função do atraso na colheita em 0, 7, 14, 21 e 28 dias. Lavras, 2001.

\begin{tabular}{lccccc}
\hline \multirow{2}{*}{ Cultivares e Linhagens } & \multicolumn{5}{c}{ Atraso na colheita (dia) } \\
\cline { 2 - 5 } & $\mathbf{0}$ & $\mathbf{7}$ & $\mathbf{1 4}$ & $\mathbf{2 1}$ & $\mathbf{2 8}$ \\
\hline Guarani & 20 & 16 & 15 & 15 & 14 \\
IAC 202 & 23 & 19 & 16 & 15 & 14 \\
Primavera & 22 & 17 & 16 & 16 & 14 \\
Caiapó & 21 & 18 & 17 & 15 & 15 \\
Canastra & 16 & 15 & 15 & 15 & 15 \\
Confiança & 15 & 17 & 14 & 16 & 15 \\
Carisma & 20 & 16 & 16 & 16 & 14 \\
MG 1043 & 22 & 17 & 16 & 15 & 14 \\
CNAs 8824 & 18 & 17 & 15 & 15 & 15 \\
CNAs 8983 & 17 & 17 & 16 & 15 & 15 \\
CNAs 8957 & 21 & 15 & 15 & 15 & 14 \\
CRO 97505 & 21 & 15 & 15 & 15 & 14 \\
\hline Média & 19,6 & 16,6 & 15,5 & 15,3 & 14,4 \\
\hline
\end{tabular}




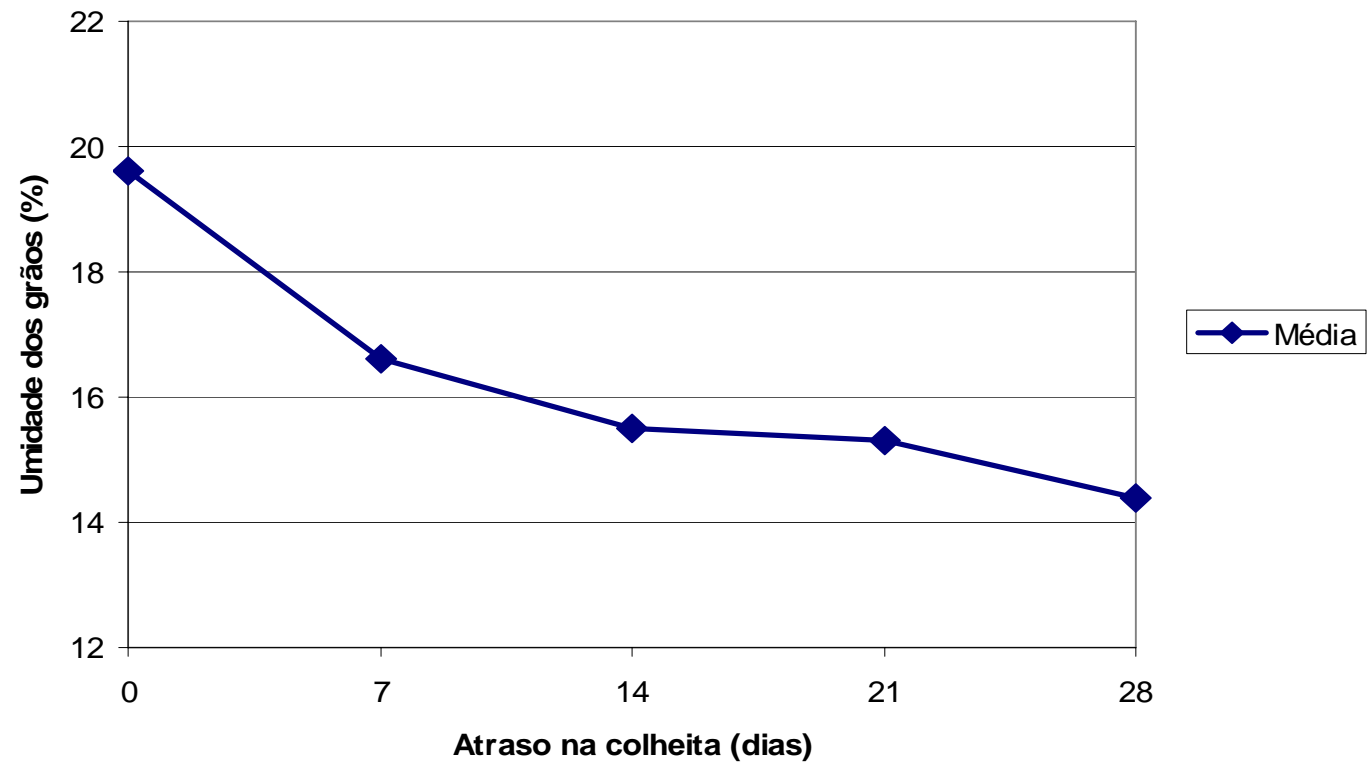

FIGURA 1 - Variação da umidade dos grãos de 12 cultivares e linhagens de arroz de terras altas em função do atraso na colheita em zero, 7, 14, 21 e 28 dias após. Lavras, 2001.

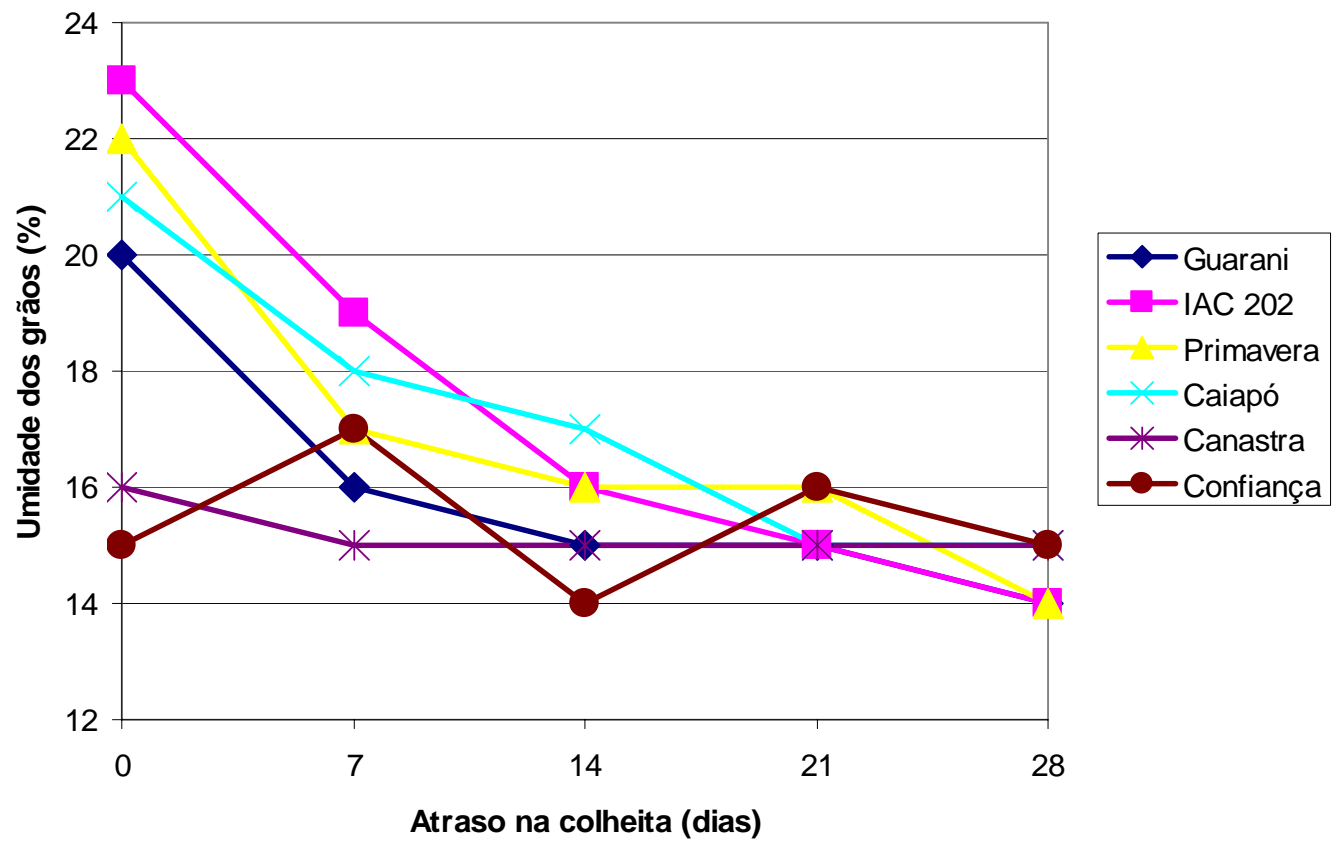

FIGURA 2 - Variação da umidade dos grãos de seis cultivares de arroz de terras altas, em função do atraso na colheita em zero, 7, 14, 21 e 28 dias após. Lavras, 2001.

Ciênc. agrotec., Lavras, v. 28, n. 5, p. 1021-1030, set.out., 2004 
Efeitos do atraso e do período de armazenamento sobre o...

Os rendimentos de grãos inteiros no beneficiamento das 12 cultivares e linhagens de arroz, em função de diferentes épocas de colheita, ou seja, na colheita, 7 , 14, 21 e 28 dias após essa ser realizada, são mostrados na Tabela 2. Observa-se que, na colheita, o rendimento médio de inteiros, envolvendo todos os materiais, foi de $58 \%$. Entretanto, à medida que se atrasou a colheita em $7,14,21$ e 28 dias, ocorreu um decréscimo sucessivo no rendimento médio de inteiros de 5, 6, 8 e 6\%, respectivamente. Por meio desse resultado, verifica-se claramente que não se deve atrasar a colheita do arroz após os grãos atingirem a umidade adequada de colheita. $\mathrm{Na}$ Figura 4 retrata-se melhor a tendência de redução de rendimento de grãos inteiros, quando se atrasa a colheita no campo; nota-se que a tendência de redução é quase linear.

Os resultados de avaliação dos rendimentos de grão inteiros em diferentes épocas de colheita, para cada material individualmente, são apresentados na Figura 5 ('Guarani', 'IAC 202', 'Primavera', 'Caiapó', 'Canastra' e 'Confiança') e Figura 6 ('Carisma', 'CNAs 8983', 'MG 1043', 'CNAs 8824', 'CNAs 8957' e 'CRO 97505'). Observando as duas figuras, nota-se que há um comportamento bastante variável entre os materiais testados. Pela Figura 5, verifica-se que a 'Caiapó', seguida da 'IAC 202', foram as cultivares que mais resistiram à quebra de grãos no beneficiamento, quando se atrasou a colheita, ao passo que a 'Guarani' foi a que exibiu menor percentual de inteiros. Quanto à Figura 6, nota-se que o melhor comportamento, no tocante a rendimento de grãos inteiros e na tolerância à quebra de grãos no bene- ficiamento, foi da linhagem CNAs 8983, seguida da CNAs 8824. Por outro lado, o pior desempenho nesse quesito foi da 'CRO 97505'.

Na Figura 7 relaciona-se a umidade de colheita com o rendimento de grãos inteiros no beneficiamento, considerando a média dos 12 materiais. Como se observa, à medida que se afasta do ponto adequado da umidade de colheita (20 a 22\%), ocorre uma queda acentuada no rendimento de inteiros. Esse resultado reforça a recomendação técnica de que a colheita deve ser realizada quando os grãos de arroz apresentarem de 20 a $22 \%$ de umidade.

Outro estudo interessante realizado nesse trabalho foi o do efeito do armazenamento no rendimento de grãos inteiros no beneficiamento. Para tanto, os grãos foram armazenados por 30, 60, 90, 120 e 150 dias após a colheita. Em cada período desses, procedeu-se à avaliação do rendimento de inteiros, cujos resultados são relatados na Tabela 3. Considerando a média de todas as cultivares e linhagens, aos 30 e 60 dias após a colheita, o rendimento de inteiros reduziu-se em $2 \%$ e $1 \%$, respectivamente. Entretanto, a partir de 90 dias, voltou a subir e, no final do período, 150 dias, ocorreu um acréscimo de $3 \%$ em relação à época da colheita. Com isso infere-se que não há problema em armazenar o arroz para comercializar na entressafra, no tocante a rendimento de inteiros, pelo contrário, é até vantajoso guardar o produto. A curva de tendência do rendimento de grãos inteiros no beneficiamento, em função dos diferentes períodos de armazenamentos, é mostrada na Figura 8.

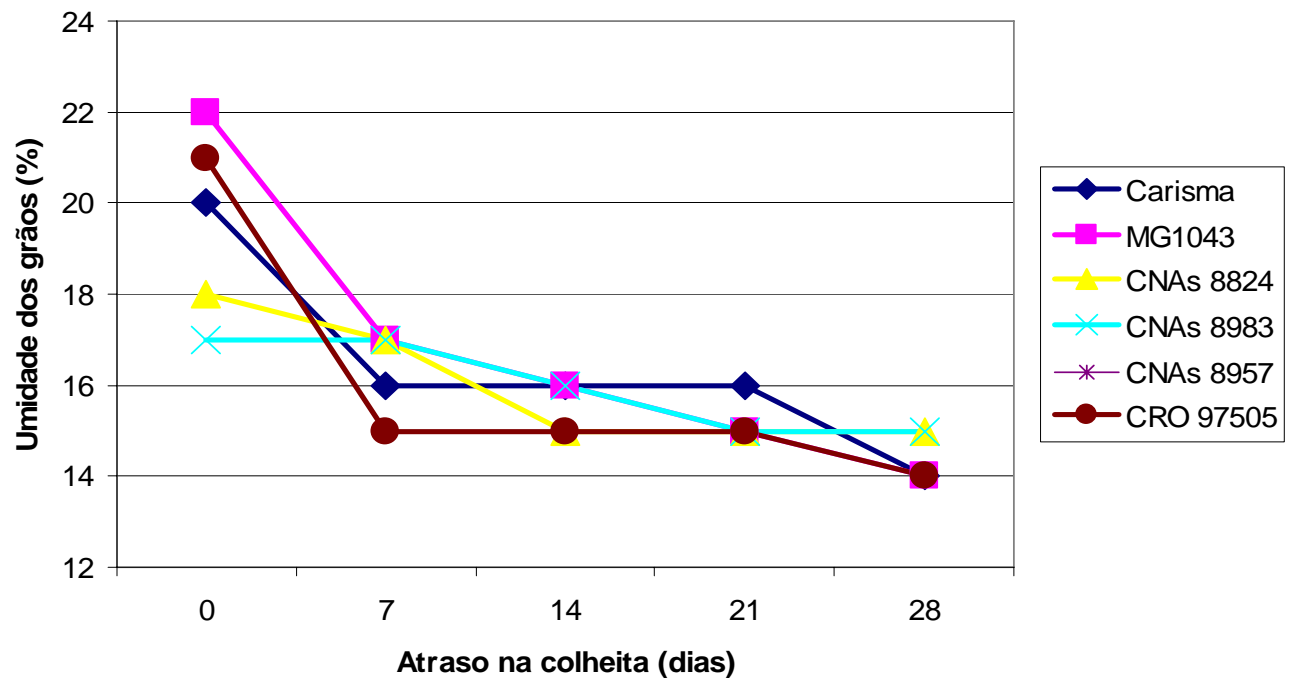

FIGURA 3 - Variação da umidade dos grãos da cultivar Carisma e de cinco linhagens de arroz de terras altas, em função do atraso na colheita em zero, 7, 14, 21 e 28 dias após, respectivamente. Lavras, 2001. 


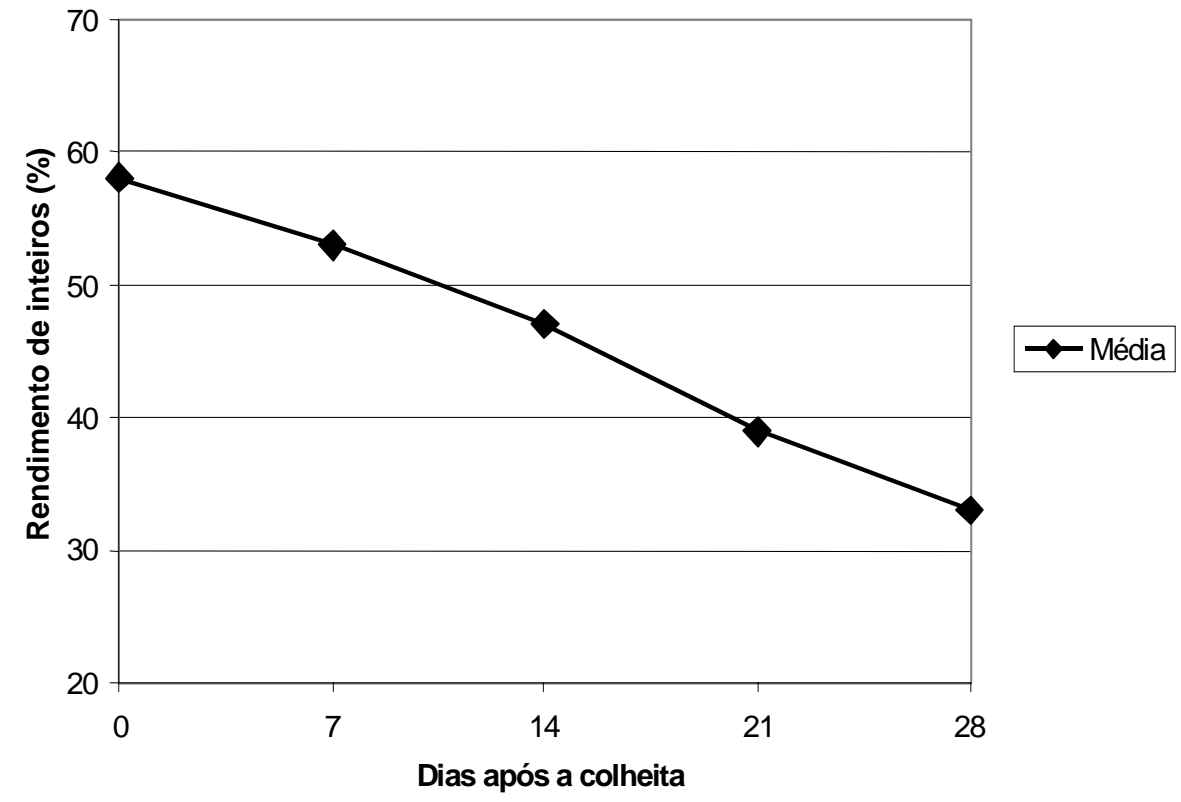

FIGURA 4 - Rendimento de grãos inteiros no beneficiamento de 12 cultivares e linhagens de arroz de terras altas, em função de cinco épocas de colheita (0, 7, 14, 21 e 28 dias após a maturação, respectivamente). Lavras, 2001.

TABELA 2 - Rendimento de grãos inteiros (\%) no beneficiamento de 12 cultivares e linhagens de arroz de terras altas, em cinco épocas de colheita (na maturação, 7, 14, 21 e 28 dias após). Lavras, 2001.

\begin{tabular}{lccccc}
\hline \multirow{2}{*}{ Cultivares e Linhagens } & \multicolumn{5}{c}{$\mathbf{N}^{\circ}$ dias após a colheita } \\
\cline { 2 - 6 } & $\mathbf{0}$ & $\mathbf{7}$ & $\mathbf{1 4}$ & $\mathbf{2 1}$ & $\mathbf{2 8}$ \\
\hline Guarani & 52 & 46 & 36 & 27 & 15 \\
IAC 202 & 53 & 57 & 47 & 46 & 43 \\
Primavera & 61 & 50 & 46 & 28 & 20 \\
Caiapó & 64 & 62 & 58 & 54 & 54 \\
Canastra & 55 & 55 & 39 & 27 & 27 \\
Confiança & 47 & 41 & 33 & 27 & 27 \\
Carisma & 57 & 55 & 50 & 44 & 34 \\
MG 1043 & 56 & 51 & 49 & 43 & 34 \\
CNAs 8824 & 67 & 63 & 57 & 49 & 37 \\
CNAs 8983 & 70 & 69 & 66 & 59 & 54 \\
CNAs 8957 & 54 & 48 & 42 & 36 & 30 \\
CRO 97505 & 60 & 43 & 39 & 31 & 25 \\
\hline Média & 58 & 53 & 47 & 39 & 33
\end{tabular}

Ciênc. agrotec., Lavras, v. 28, n. 5, p. 1021-1030, set.out., 2004 


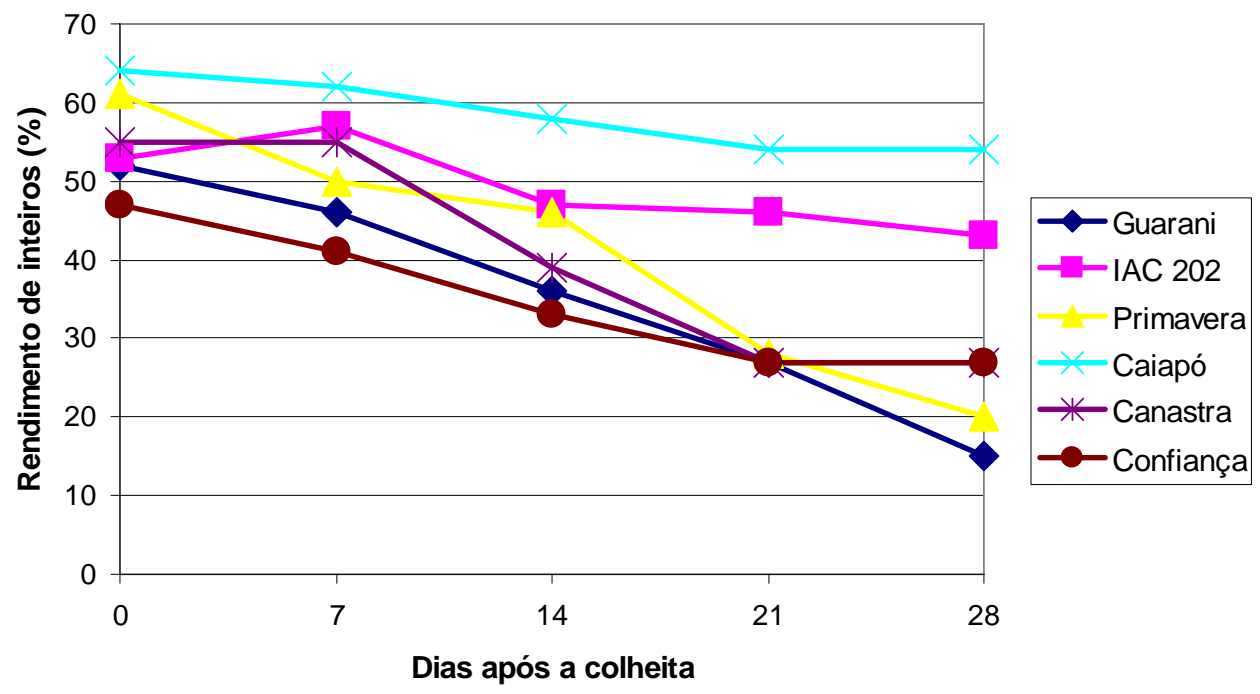

FIGURA 5 - Rendimento de grãos inteiros no beneficiamento de seis cultivares de arroz de terras altas, em função de cinco épocas de colheita (na maturação, 7, 14, 21 e 28 dias após a colheita, respectivamente). Lavras, 2001.

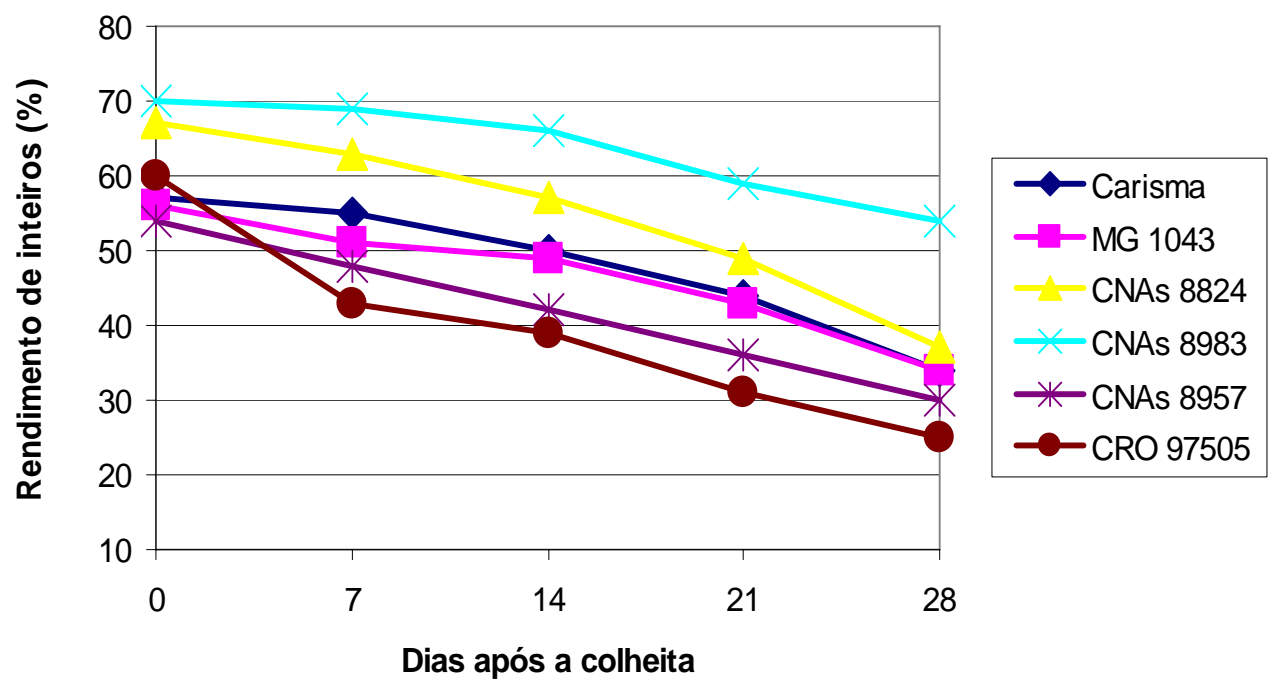

FIGURA 6 - Rendimento de grãos inteiros no beneficiamento da cultivar carisma e de cinco linhagens de arroz de terras altas, em função de cinco épocas de colheita (na maturação, 7, 14, 21 e 28 dias após a colheita, respectivamente). Lavras, 2001. 


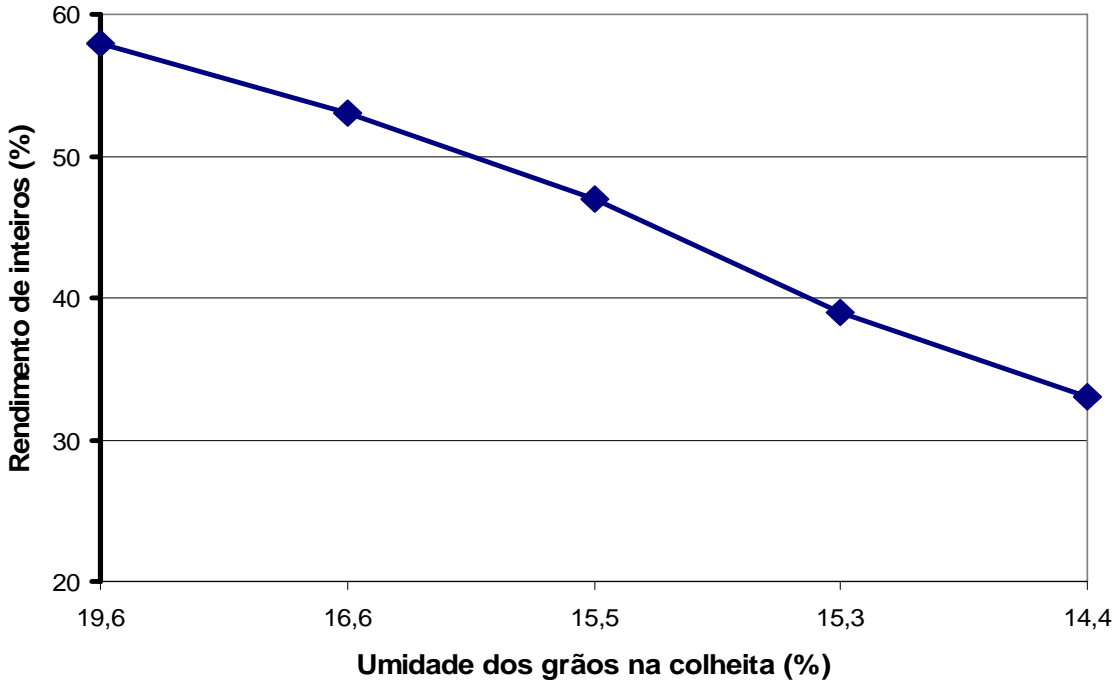

FIGURA 7 - Relação entre a umidade média dos grãos na colheita e o rendimento médio de grãos inteiros no beneficiamento de 12 cultivares e linhagens de arroz de terras altas. Lavras, 2001.

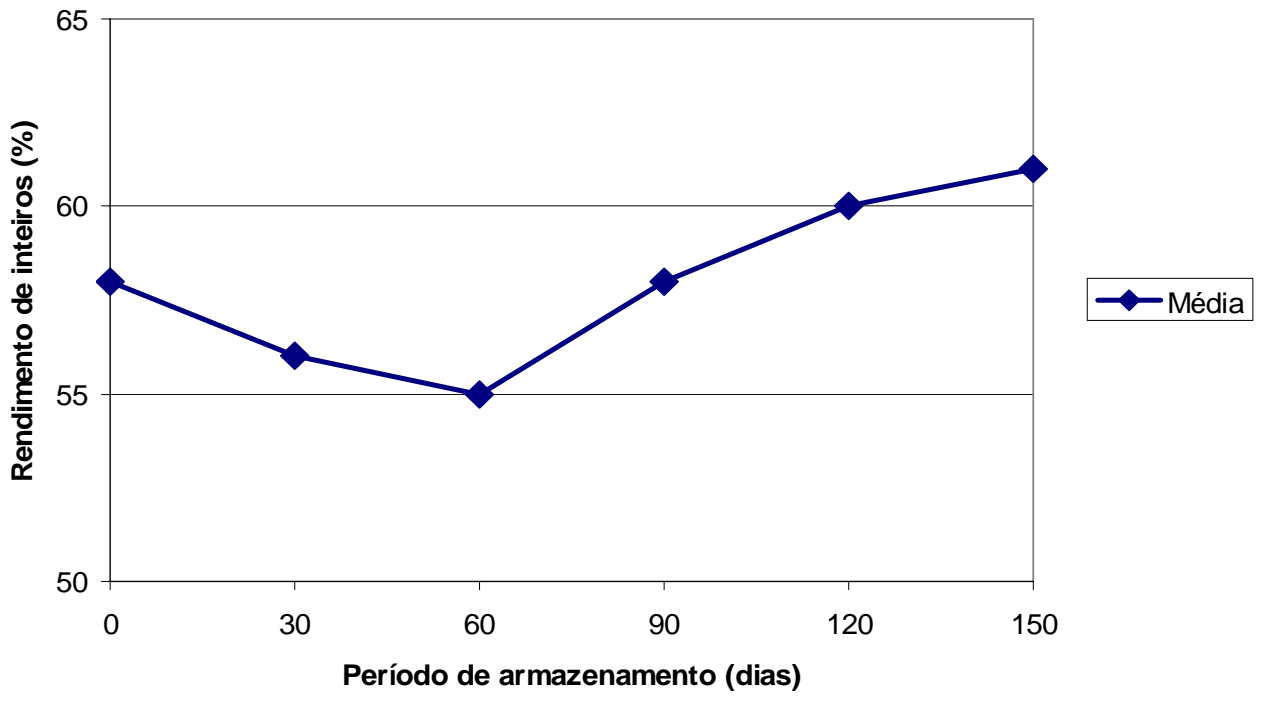

FIGURA 8 - Efeito de seis períodos de armazenamento (0, 30, 60, 90, 120 e 150 dias após a colheita, respectivamente) sobre o rendimento de grãos inteiros no beneficiamento, considerando a média de 12 cultivares e linhagens de arroz de terras altas. Lavras, 2001.

Entretanto, o efeito do armazenamento sobre o rendimento de inteiros é variável entre os diferentes materiais (Figuras 9 e 10). Alguns deles, como são os casos da 'Caiapó' (Figura 9) e 'CNAs 8983' (Figura 10), têm um comportamento quase constante ao longo do armazena- mento; outras, como a 'Canastra' (Figura 9), têm uma tendência crescente de rendimento de inteiros, com o armazenamento. Mas a maioria exibe uma tendência decrescente nos dois primeiros períodos (30 e 60 dias), voltando a ser crescente nos demais (Figuras 9 e 10). 
Efeitos do atraso e do período de armazenamento sobre o...

1029

TABELA 3 - Rendimento de grãos inteiros de 12 cultivares e linhagens de arroz de terras altas, aos 0, 30, 60, 90, 120 e 150 dias após a colheita. Lavras, 2001.

\begin{tabular}{lcccccc}
\hline \multirow{2}{*}{ Cultivares e Linhagens } & \multicolumn{7}{c}{ Período de armazenamento(dia) } \\
\cline { 2 - 7 } & $\mathbf{0}$ & $\mathbf{3 0}$ & $\mathbf{6 0}$ & $\mathbf{9 0}$ & $\mathbf{1 2 0}$ & $\mathbf{1 5 0}$ \\
\hline Guarani & 52 & 51 & 52 & 57 & 57 & 58 \\
IAC 202 & 53 & 57 & 56 & 61 & 61 & 62 \\
Primavera & 61 & 55 & 53 & 60 & 60 & 61 \\
Caiapó & 64 & 61 & 61 & 62 & 64 & 64 \\
Canastra & 55 & 57 & 57 & 59 & 60 & 61 \\
Confiança & 47 & 42 & 43 & 46 & 47 & 49 \\
Carisma & 57 & 52 & 50 & 51 & 57 & 58 \\
MG 1043 & 56 & 54 & 50 & 56 & 60 & 66 \\
CNAs8824 & 67 & 59 & 57 & 61 & 62 & 64 \\
CNAs8983 & 71 & 67 & 67 & 68 & 68 & 69 \\
CNAs8957 & 54 & 58 & 56 & 61 & 61 & 62 \\
CRO97505 & 60 & 55 & 54 & 56 & 58 & 59 \\
\hline Média & 58 & 56 & 55 & 58 & 60 & 61 \\
\hline
\end{tabular}

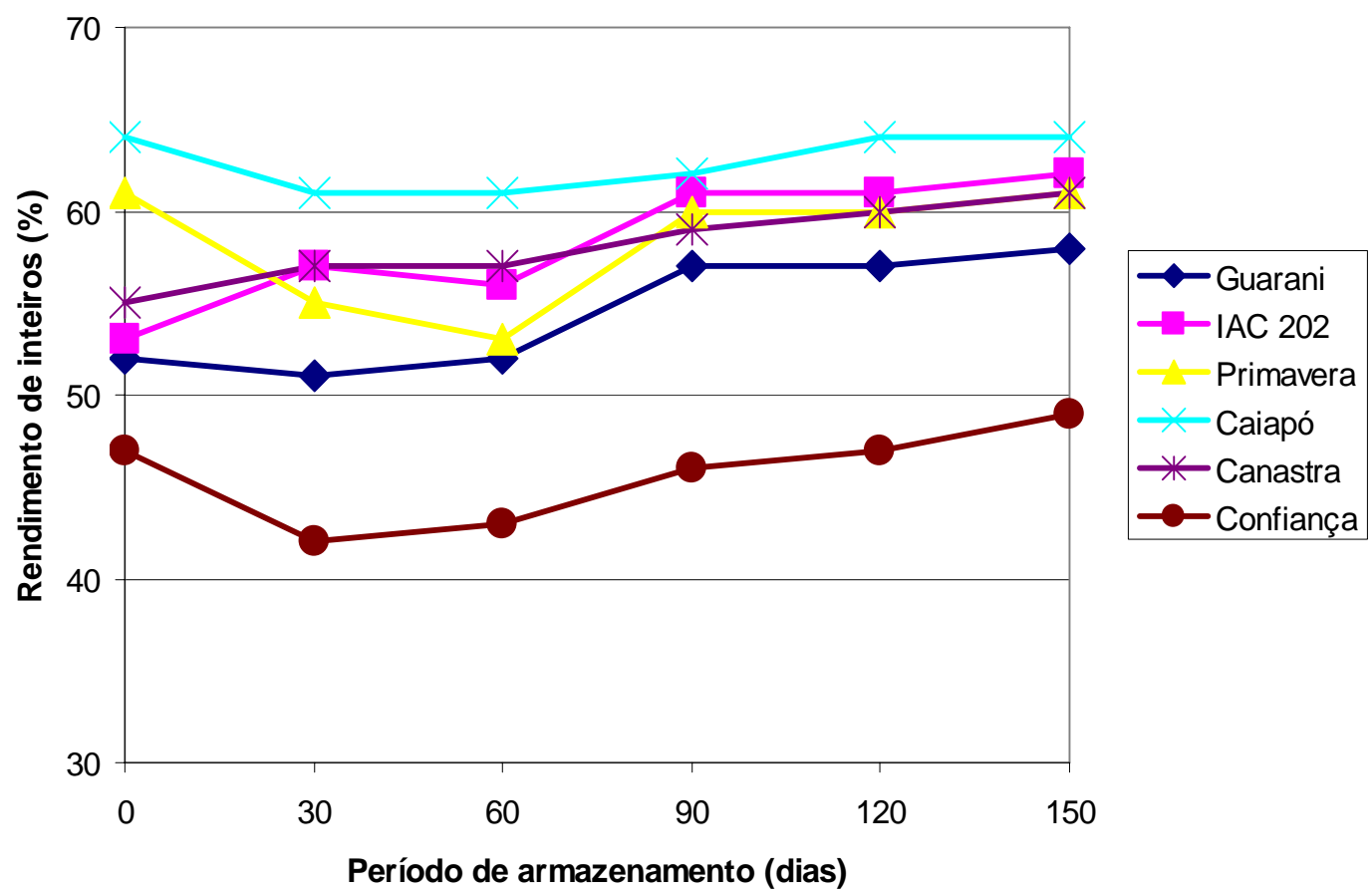

FIGURA 9 - Efeito de seis períodos de armazenamento (0, 30, 60, 90, 120 e 150 dias após a colheita, respectivamente) sobre o rendimento de grãos inteiros no beneficiamento de seis cultivares de arroz de terras altas. Lavras, 2001. 


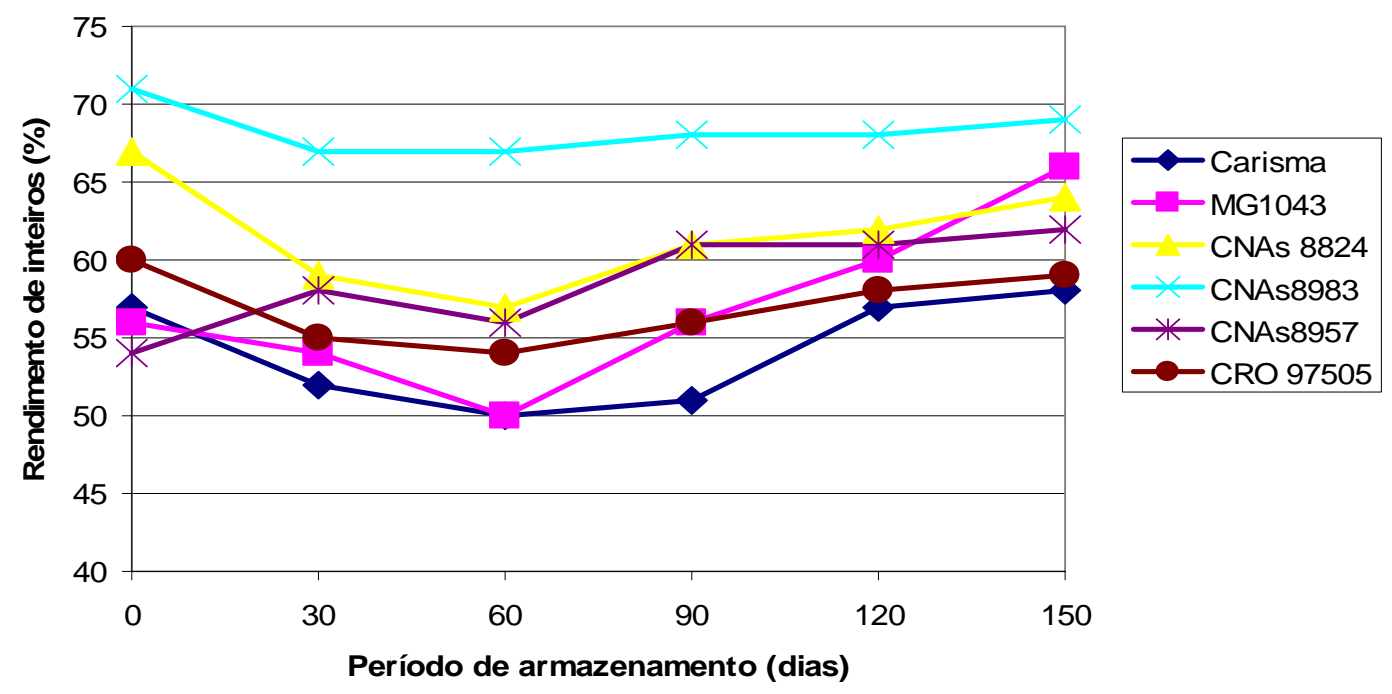

FIGURA 10 - Efeito de seis períodos de armazenamento (0, 30, 60, 90, 120 e 150 dias após a colheita, respectivamente) sobre o rendimento de grãos inteiros no beneficiamento da cultivar Carisma e de cinco linhagens de arroz de terras altas. Lavras, 2001.

\section{CONCLUSÕES}

a) A colheita do arroz deve ser realizada quando os grãos atingirem a umidade próxima de $20 \%$.

b) A cultivar Caiapó e a linhagem CNAs 8983 podem sofrer atraso na colheita, sem maiores riscos de reduzir significativamente o rendimento de grãos inteiros no beneficiamento.

c) $\mathrm{O}$ armazenamento do arroz não causa redução do percentual de grãos inteiros no beneficiamento, podendo até ser benéfico.

\section{AGRADECIMENTOS}

À Fapemig e à Embrapa, pelo financiamento do projeto de pesquisa "Melhoramento Genético do Arrozde-Sequeiro para Terras Altas e Várzeas”, as quais deram suporte para a realização deste trabalho.

Ao CNPq, pela concessão de bolsa de iniciação científica ao estudante autor deste artigo.

À Epamig, pela parceria no desenvolvimento do projeto, apoiando a condução dos ensaios na Fazenda Experimental de Lavras.

\section{REFERÊNCIAS BIBLIOGRÁFICAS}

BRESEGHELLO, F.; STONE, L. F. Tecnologia para terras altas. Santo Antônio de Goiás: EMBRAPA Arroz e Feijão, 1998. 161 p.
CASTRO, E. da M. de; VIEIRA, N. R. de A.; RABELO, R. R.; SILVA, S. A. da. Qualidade de grãos em arroz. Santo Antônio de Goiás: EMBRAPA Arroz e Feijão, 1999. 30 p. (Circular Técnica, 34).

EMPRESA BRASILEIRA DE PESQUISA AGROPECUÁRIA. A cultura de arroz no Brasil. Santo Antônio de Goiás: EMBRAPA Arroz e Feijão, 1999. 633 p.

EMPRESA DE PESQUISA AGROPECUÁRIA DE MINAS GERAIS. Influência do ponto de colheita na qualidade de grãos de cultivares de arroz. Belo Horizonte, 1983. Relatório de pesquisa apresentado à Embrapa em 1983.

FERNANDES, G. M. B.; AMORIM NETO, S. Qualidade do arroz em função da época de colheita e do teor de umidade no beneficiamento em engenho. Rio de Janeiro: Pesagro, 1987. 4 p. (Comunicado Técnico, 180).

HESSE, S. R. Maturação fisiológica das sementes de arroz (Oryza sativa Linnaeus) cv. IAC 47. Porto velho: EMBRAPA/UEPAE, 1983. 4 p. (Pesquisa em andamento, 54).

SOARES, A. A. Cultura do arroz. Lavras: UFLA, 2001. 111 p. (Textos acadêmicos, 7). 